\title{
Photovoltaic MPPT Algorithm Based on Hybrid Boost Converter and Variable Step Size Incremental Conductance
}

\author{
Yiwei Ma ${ }^{*}$, Fuxing Wang, Zongsheng Huang, Qin Feng and Changhao Piao \\ School of Automation, Chongqing University of Posts and Telecommunication, Chongqing, China
}

\begin{abstract}
Aiming at the problem of low voltage gain of traditional boost converter and the incompatibility of tracking speed and tracking accuracy with the traditional incremental conductance algorithm (INC), this paper uses the hybrid boost converter as the DC/DC converter of photovoltaic system, and designs the variable step size INC algorithm control strategy to achieve Maximum power point tracking (MPPT) of photovoltaic. Simulink simulation model verifies the feasibility of the proposed algorithm, which effectively improves the output voltage and power generation efficiency of the photovoltaic system.
\end{abstract}

\section{Introduction}

With the widespread application of new energy power generation technologies such as photovoltaic cells, the market has put forward higher requirements on the output voltage and power generation efficiency of new energy power generation devices. Therefore, $\mathrm{DC} / \mathrm{DC}$ converters and maximum power tracking technologies are needed to increase power generation output voltage and power generation efficiency [1-2]. The traditional boost converter is the most commonly used DC/DC converter in photovoltaic, but its output voltage can reach a larger value only when the duty cycle is close to 1 , so the output voltage is particularly limited. Literature [3] used cascaded boost converters to achieve high voltage gain, but each stage has a power switch tube, which increases the difficulty of control and the cost is higher. The quadratic boost converter used only one switch tube, and the boost radio is doubled compared to the traditional boost converter. However, its boost capability still has a certain amount of room for improvement [4]. Literature [5] proposed a hybrid boost converter with the switch-inductor structure based on the quadratic boost converter, which not only improves the boosting capability, but also improves the efficiency of photovoltaic. Due to the non-linear characteristics of the photovoltaic cells [6], it is necessary to track the MPP through MPPT to improve the power generation efficiency of photovoltaic cells. The INC algorithm is widely used because of its simple structure and easy implementation [7-8]. But its step size is fixed, it is easy to cause misjudgement when the light intensity changes suddenly, and the tracking speed and tracking accuracy are not coordinated [9]. The existing research literatures usually only solves the problem of low output voltage or MPPT of photovoltaic, without comprehensively considering the output

\footnotetext{
*Corresponding author: mayw@cqupt.edu.cn
} 
voltage and power generation efficiency of photovoltaic. Therefore, in this paper, the hybrid boost converter is used as the DC/DC converter of photovoltaic, and variable step size INC algorithm is used to track the maximum power of photovoltaic cells, which can effectively improve the output voltage and power generation efficiency of photovoltaic system.

\section{The hybrid boost converter}

\subsection{Topology structure of hybrid boost converter}

The topological structure of the hybrid boost converter is shown in Figure 1. It is composed of 1 switch inductor, 2 capacitors $C_{1}, C_{2}, 1$ power switch tube $S, 3$ diodes $D_{3}, D_{4}, D_{5}$ and an inductor $L_{3}$. Among them, the switch inductor is composed of 2 inductors $L_{1}, L_{2}$ and 3 diodes $D_{1}, D_{2}, D_{12}$, which is to replace the input inductor in the traditional boost converter. The boost of the hybrid boost converter is $(1+\mathrm{Dt})$ times higher than that of the quadratic boost converter, and its boost ratio is:

$$
\frac{U_{o u t}}{E}=\frac{1+D t}{(1-D t)^{2}}
$$

Where Dt is the duty cycle.

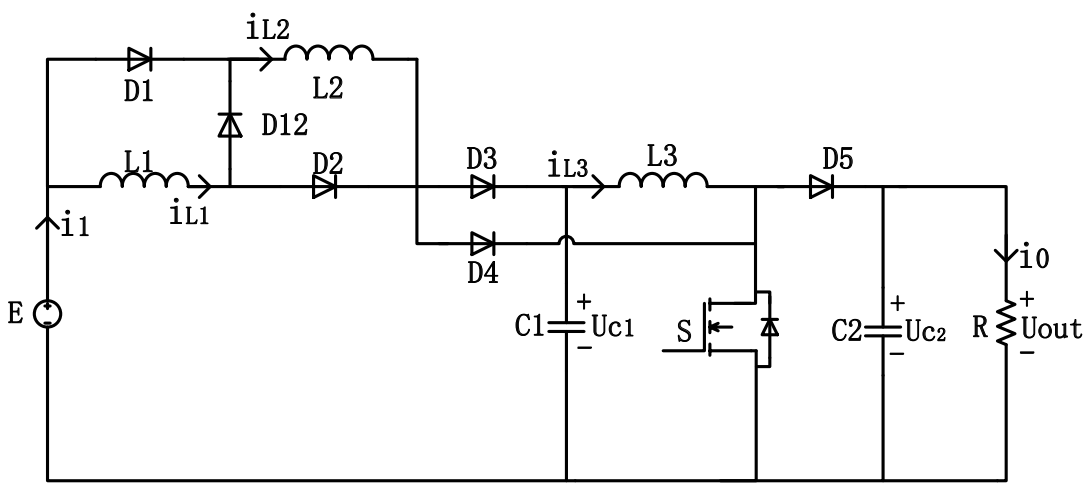

Fig. 1. Topology structure of hybrid boost converter

\subsection{Analysis of working modes}

The size of the inductance $L_{1}, L_{2}$ will affect the working mode of the hybrid boost converter, but its boost ratio remains unchanged, both are $U_{\text {out }} / E=(1+D t) /(1-D t)^{2}[4]$. Therefore, the hybrid boost converter in this paper takes inductance $L_{1}=L_{2}$. The working mode of the hybrid boost converter is analysed below.

In different periods of time, the power switch $\mathrm{S}$ can be divided into two states: on and off. The inductance and capacitance in the circuit are charged and discharged alternately. Working mode $1\left(t_{0} \leq t \leq t_{0}+D T\right)$, the power switch $\mathrm{S}$ is turned on, $D_{1}, D_{2}, D_{4}$ are turned on, and $D_{3}, D_{5}, D_{12}$ are turned off; at this time, the power supply E charges the inductor $L_{1}$ and $L_{2}$, the capacitor $C_{1}$ charges the inductor $L_{3}$, and the capacitor $C_{2}$ provides energy for the load. The equivalent circuit is shown in Figure 2. Working mode $2\left(t_{0}+D T \leq t \leq t_{0}+\right.$ $T$ ), the power switch $S$ is cut off, $D_{1}, D_{2}, D_{4}$ are turned off, and $D_{3}, D_{5}, D_{12}$ are on; the power 
supply $\mathrm{E}$ and the inductor $L_{1}, L_{2}$ release energy to the capacitor $C_{1}$ and the inductor $L_{3}$, while the inductor $L_{3}$ supplies energy to the load and charges the capacitor $C_{2}$. The equivalent circuit is shown in Figure 3. According to the on-off conditions of the switch $S$ in different modes and the volt-second balance characteristics of the inductance element, we can get:

$$
\left\{\begin{array}{l}
U_{C 1} D t+\left(U_{C 1}-U_{C 2}\right)(1-D t)=0 \\
E D t+\left(E-U_{C 1}\right) \frac{L_{1}}{L_{1}+L_{2}}(1-D t)=0 \\
E D t+\left(E-U_{C 1}\right) \frac{L_{2}}{L_{1}+L_{2}}(1-D t)=0 \\
U_{C 2}=U_{\text {out }}
\end{array}\right.
$$

Where $U_{C 1}$ and $U_{C 2}$ are the terminal voltages of capacitors $C_{1}$ and $C_{2}$, and $\mathrm{E}$ is the DC power supply. When $L_{1}=L_{2}$, the boost ratio of the hybrid boost converter in continuous working mode is:

$$
\frac{U_{\text {out }}}{E}=\frac{1+D}{(1-D)^{2}}
$$

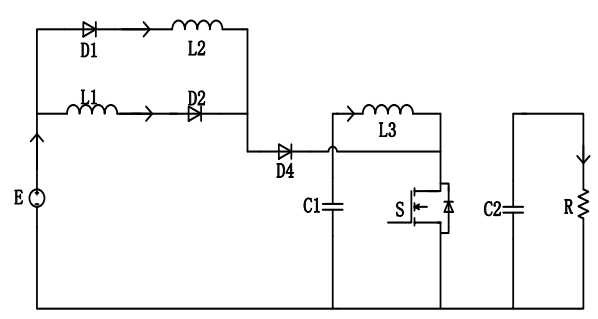

Fig. 2. Working mode 1

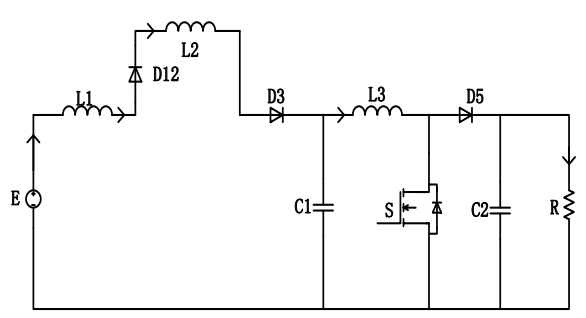

Fig. 3. Working mode 2

\subsection{Characteristic analysis}

Figure 4 shows the output voltage curves of the three boost converters when the DC input voltages are all $10 \mathrm{~V}$ and the duty cycle $\mathrm{Dt}=0.5$.

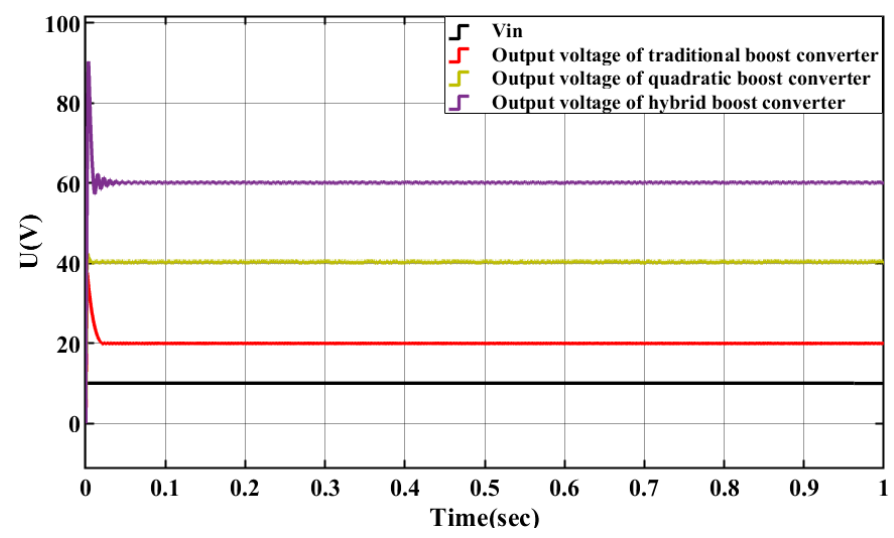

Fig. 4. The output voltage curves of the three boost converter 
Figure. 3 shows that when the input voltage $U_{\text {in }}=10 \mathrm{~V}$, Dt $=0.5$, the traditional boost converter $U_{\text {out }}=20 \mathrm{~V}$, which meets its boost ratio $\frac{\mathrm{U}_{\mathrm{out}}}{\mathrm{U}_{\mathrm{in}}}=\frac{1}{1-\mathrm{Dt}}$; the quadratic boost converter $\mathrm{U}_{\text {out }}=40 \mathrm{~V}$, which also satisfies its boost ratio $\frac{\mathrm{U}_{\text {out }}}{\mathrm{U}_{\text {in }}}=\frac{1}{(1-\mathrm{Dt})^{2}}$; the hybrid boost converter $U_{\text {out }}=60 \mathrm{~V}$ also satisfies its boost ratio $\frac{U_{\text {out }}}{U_{\text {in }}}=\frac{1+D t}{(1-D t)^{2}}$. Therefore, the hybrid boost converter has obvious advantages in boost radio compared with the other two boost converter, which can meet the demand of high boost radio of the PV system.

\section{Variable step size incremental conductance algorithm}

In this paper, the variable step size INC is used to track the MPP of the PV system. Compared with the traditional INC algorithm, this method takes into account the relationship between tracking speed and tracking accuracy.

The step length of the variable step size INC algorithm is to automatically change the size of the step length according to whether the operating point is near the MPP, so as to minimize the oscillation when the power is in a steady state. When the operating point is far away from the maximum power point, a larger step size is used to ensure the maximum tracking speed; when the operating point is close to MPPT, the step size is reduced to reduce oscillation and realize the maximize tracking accuracy. The step modification equation is:

$$
\left\{\begin{array}{l}
\left|\frac{d P}{d U}\right|=\left|\frac{P(m)-P(m-1)}{V(m)-V(m-1)}\right| \\
\text { step }=M \times\left|\frac{d P}{d U}\right| \\
D t(m)=D t(m-1) \pm s t e p
\end{array}\right.
$$

Where $\mathrm{M}$ is the tracking coefficient.

The variable step size INC algorithm control flow chart is shown as in Figure 5.

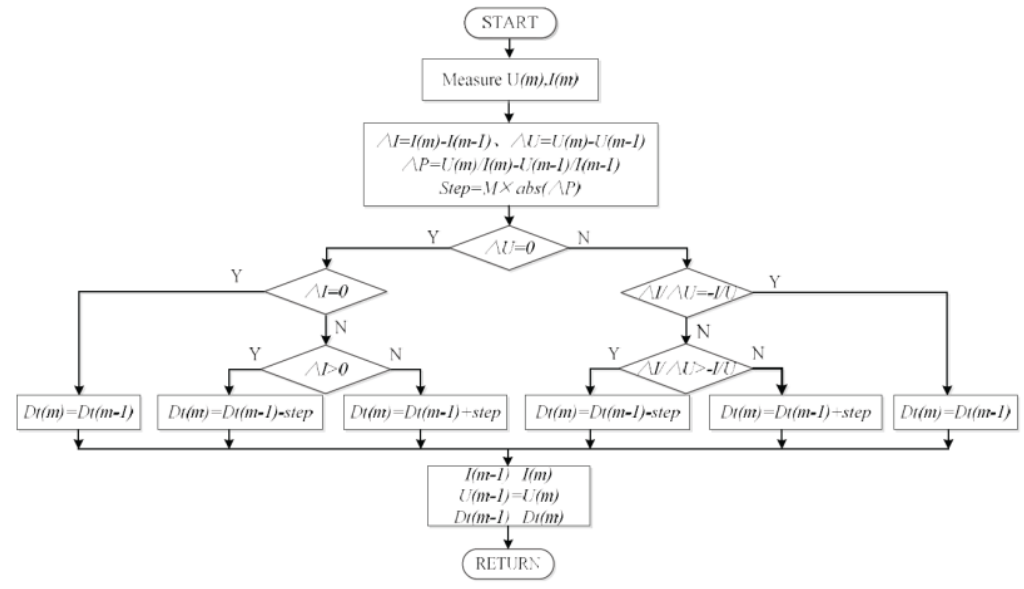

Fig. 5.The variable step size INC algorithm control flow chart 


\section{Simulation verification and result analysis}

In this paper, a photovoltaic system MPPT algorithm simulation model based on a hybrid boost converter and variable step size INC algorithm is built on the Simulink, as shown in Figure 6.

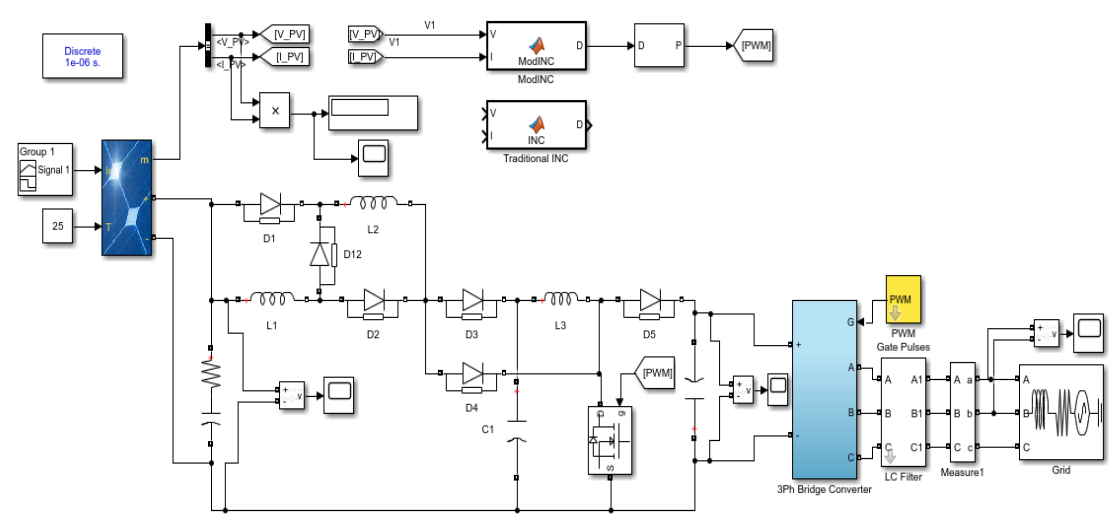

Fig. 6. Simulation model of photovoltaic MPPT algorithm based on hybrid boost converter and variable step size INC

In order to study the tracking of the MPP when the light intensity changes suddenly, it is divided into two situations: a sudden increase in light intensity and a sudden decrease in light intensity:

i. Sudden increase in light intensity, the light intensity changes from $1000 \mathrm{~W} / \mathrm{m}^{2}$ to $500 \mathrm{~W} / \mathrm{m}^{2}$

ii. Sudden decrease in light intensity, the light intensity changes from $500 \mathrm{~W} / \mathrm{m}^{2}$ to $800 \mathrm{~W} / \mathrm{m}^{2}$

Figures 7 and 8 show the MPPT output curve based on the traditional INC algorithm and the variable step size INC algorithm when the light intensity suddenly increases.

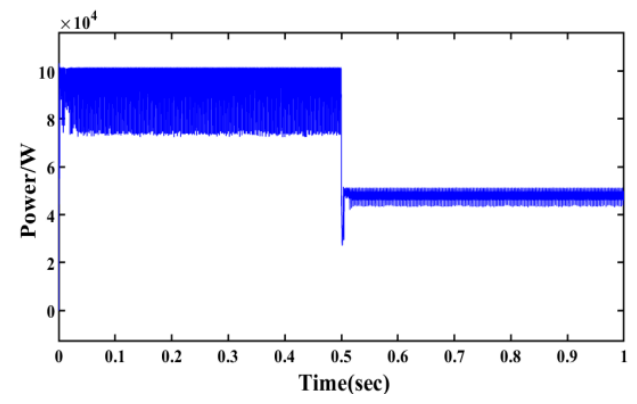

Fig. 7. Output power curve of traditional INC algorithm

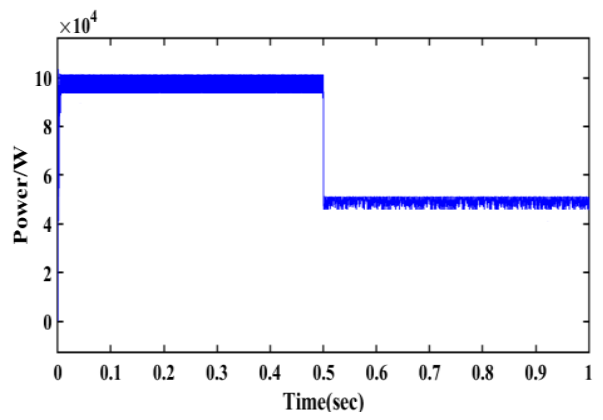

Fig. 8. Output power curve of variable step size INC algorithm

Figures 9 and 10 show the MPPT output curve based on the traditional INC algorithm and the variable step size INC algorithm when the light intensity suddenly decreases. 


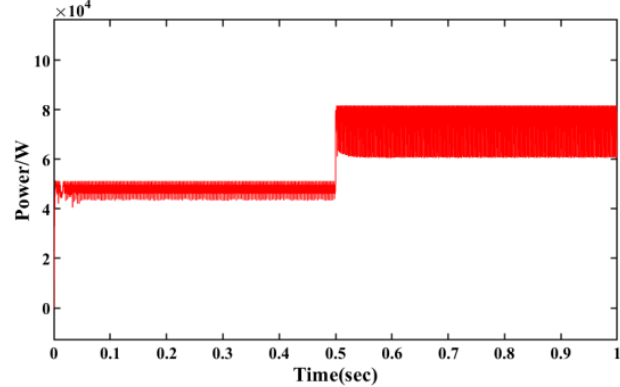

Fig. 9. Output power curve of traditional INC algorithm

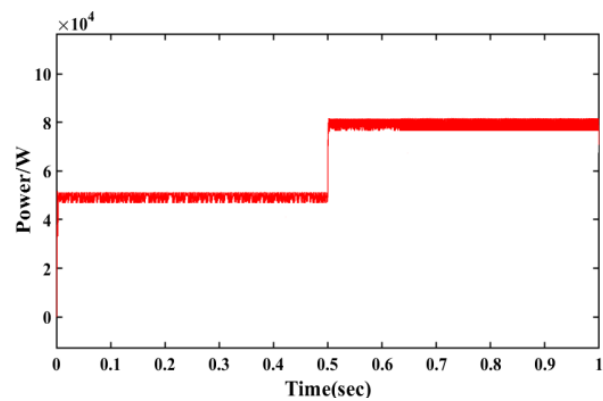

Fig. 10. Output power curve of variable step size INC algorithm

From Figure 7,Figure 8, Figure 9 and Figure 10 , we can see that when the light intensity suddenly increases or decreases, the variable step-size INC algorithm has smaller fluctuations than the traditional INC algorithm, and it can quickly track the MPP. The traditional INC algorithm has large steady-state oscillation amplitude, causing energy loss. The variable step size INC algorithm has small steady-state oscillation amplitude, which shows that the tracking speed and tracking accuracy of the variable-step size INC algorithm are better than the traditional INC algorithm. At the same time, the hybrid Boost circuit achieves a boost ratio of more than 2.5 times when the duty cycle is less than 0.3 . Therefore, it is of great help to increase the output voltage of the photovoltaic system.

To sum up, when the external conditions suddenly change, the photovoltaic system algorithm based on the hybrid boost converter and variable step size INC can quickly track the MPP, and the steady-state power oscillation is small and the boost ratio is high, which meets the design requirements.

\section{Conclusion}

In this paper, the hybrid Boost converter and the variable step size INC algorithm are used to the photovoltaic, and the Simulink simulation model verifies the feasibility of the method. The results indicates that the hybrid Boost converter can effectively increase the output voltage of the photovoltaic under the condition of low duty cycle; and the variable-step size INC algorithm realizes the maximum power point tracking of the photovoltaic cell. The contradiction between tracking speed and tracking accuracy in the tracking process is solved, and the combination of the two effectively improves the output voltage and power generation efficiency of the photovoltaic system.

\section{Acknowledgments}

This research was supported by the National Natural Science Foundation of China (No.61703068 \& 61673079) and the Research and Training Project of Chongqing University of Posts and Telecommunications (A2020-249).

\section{Reference}

[1] Li M and Huang L W 2018 Research on MPPT of Secondary Boost Converter Photovoltaic System (China : Electric drive) pp 78-81 
[2] Xiong L S and Liu X K 2014 Small-signal model of photovoltaic power generation system and global optimization design method of controller parameters (China : Power grid technology) pp 1234-41

[3] Li K P 2016 Research on Switched Inductor Quadratic Boost Converter (Beijing: Beijing University of Science and Technology Information) pp 23-36

[4] N. Boujelben, F. Masmoudi and M. Djemel, 2017 Design and comparison of quadratic boost and double cascade boost converters with boost converter pp 245-252

[5] Li K P, Zhang Q J and Wang J H 2017 Hybrid quadratic Boost DC/DC converter based on switched inductance (China : Journal of Liaoning Technical University) pp 865-871

[6] Dang C L, Li J H and Chen W Q 2017 Engineering practical model and simulation of photovoltaic cells (China : Automation and instrumentation) pp 5-8.

[7] Xu L B, Cheng N F, Yang J J and Liu P P 2020 Improved INC algorithm for rapid changes in light intensity (China : New Electrician and Energy Technology) pp 56-65.

[8] Liu F, Duan S and Liu F 2008 A variable step size INC MPPT method for PV systems IEEE Transactions on Industrial Electronics pp 2622-28.

[9] Guan X Q and He A R 2018 Analysis and Improvement Strategy of Conductance Increment Method in MPPT of Photovoltaic System (Anhui : Journal of Anhui University of Science and Technology) pp 81-86.

[10] Man D 2016 Power point tracking of photovoltaic power generation system based on variable step length method ISA Transactions pp 30-38.

[11] Xia X 2019 Analysis of Maximum Power Point Tracking Algorithm for Photovoltaic Power Generation System (China : Science and Technology Innovation and Application) pp 53-55

[12] Belkaid A, Colak I and Isik O 2016 Photovoltaic maximum power point tracking under fast varying of solar radiation Applied Energy pp 523-530.

[13] Motahhir S, El Ghzizal A, Sebti S, et al 2018 Model of photovoltaic system with modified incremental conductance algorithm for fast changes of irradiance International Journal of Photoenergy pp 1-13.

[14]Josep M G, Qiang M and Shan M W 2011 A novel improved variable step-size incremental resistance MPPT method for PV systems IEEE Transactions on Industrial Electronics pp 2427-43.

[15] Yan Z W, Wang Z H, Li J 2020 Improved photovoltaic maximum power tracking control strategy based on double exponential function variable step conductance increment method (China : Science Technology and Engineering) pp 9904-10 